Session 2793

\title{
Customizable Lectures, Assignments, and Virtual Classrooms for Professionals
}

\author{
Robin Qiu \\ Division of Engineering \\ Penn State Great Valley \\ Malvern, PA 19355
}

\author{
Jane Xue \\ GL AgilityTech, Inc. \\ Collegeville, PA 19426
}

\begin{abstract}
A designated class for professionals could be quite different from one for college students due to a variety of professionals in light of attendees' totally different profiles. For instance, each individual has different background, work experience, course expectation, work schedule, and so forth. Virtual classes powered by advanced network computing and web technologies are an excellent and cost-effective solution to providing professionals with full accesses to well-developed college or training courses by eliminating time and location limitation. In addition, savvy information about individuals, such as education background, work experience, and course expectations, can be collected and archived. When knowledge-based algorithms are used to tailor course materials and assignments for each individual based on his/her saved dossier, the needs of an individual professional can be completely satisfied. Ease of use, interactions, and real time responses are essential implicit characteristics of a virtual classroom. Enabled Internet technologies and artificial intelligence make this kind of learning environment reality.
\end{abstract}

\section{Introduction}

Different from most full-time college students, professionals most likely get trained in different continue education schools/centers at night or on weekend although some intensive training could take place daily or weekly. Professionals with different course expectations, work schedules, work experience, and even totally different education backgrounds could take the same course. Undoubtedly those differences make jobs difficult for everyone involved in the training process, such as management for staff, teaching for an instructor, and learning for an trainee. Therefore, it is extremely important for a professional training school/center to have a well-defined e-learning or e-education system in place to manage trainees' personal information, help instructors improve their teaching qualities, and provide trainees' with sufficient flexibility to access the well-developed and properly suitable courses. The ultimate goal is to retain high trainees' satisfaction by meeting their career development objectives from time to time.

There are many kinds of school course management systems. Typically they are used to schedule courses, manage students/trainees' registrations, and provide on-line transcripts and payment 
services. Beyond these administration services a well-developed e-learning or e-education system should also have the following functions in order to meet the current needs of professional training schools/centers.

From staff perspectives:

- Real-time profile (e.g., course expectations, work schedules, work experience, and backgrounds) for individual trainee should be able to be viewed;

- Best offers (e.g., training plan, course availability, teaching schedules, and prices, and financial aids, etc.) based on what is known about a particular trainee should be able to be provided using different contact media (i.e., email, phone, fax, and mail);

- Historical data regarding school/center, programs, courses, instructors, and trainees should be available;

- Customized offers based on individual profile should be able to be retrieved;

- Alerting on scheduled services should be available;

- Large-volume email campaigns can be conducted efficiently and cost-effectively;

- General campaign management should be available;

- Reporting and analysis of the school/center, staffs, instructors, and trainees should be available.

From instructor perspectives:

- Real-time profile (e.g., course expectations, work schedules, work experience, and backgrounds) for individual trainee in his/her class should be able to be viewed;

- Class profile should be able to be summarized and retrieved;

- Lecture materials, assignments, project information, and messages for the assigned course should be able to be manipulated.

- Virtual classroom operations (e.g., on-line grading, chat rooms, whiteboard, and video conferencing) should be available; and

- Trainees' feedback should be provided in time.

From professional perspective:

- Based on individual profile, customized lecture materials, assignments, and project information for the registered course should be able to be retrieved.

- Interactive media (e.g., chat rooms, whiteboard, and video conferencing) should be available for having direct interactions with the instructor or other classmates.

- Interfaces to updating personal profile (e.g., course expectations, work schedules, work experience, and education backgrounds) should be available; and

- On-line homework and project submission mechanisms should be provided.

There are many articles and existing commercial solutions addressing how to use enabling technologies to design and develop e-learning or e-education system, build infrastructures to deliver the promised real-time responses, or improve system effectiveness to promote the service quality. This article discusses how an intelligent e-education system will be able to provide/enhance the above functions to improve professional trainee's satisfaction. The remainder of this article is organized as follows. Section 2 provides a brief discussion of existing solutions. Section 3 discusses the intelligent e-Education System for Professionals called myCareer developed by GL AgilityTech, Inc. At last, Section 4 gives conclusion of this article. 


\section{Literature Review and Existing Solutions}

Many e-learning or e-education systems have been developed since the emergence of the Internet Technologies. To improve the efficiency and quality service of school administration, most institutions have adopted web-based student registration systems one way or another. A lot of institutions have also deployed different kinds of on-line course systems, aiming in providing either on-campus or off-campus students with capabilities of accessing well developed course materials in a virtual classroom environment.

Tsang et al [11] introduce a multimedia distance learning system on the Internet using the basic web technologies, such as TCP/IP, HTML, Java, and SQL. Major functions include videoconference, course content authoring, whiteboard, chat room, and assignment handler. Their idea of the virtual classrooms is to extend, complement, or perhaps even replace current physical classrooms using the web-based technologies.

By focusing on an application in a virtual university environment, Trajlovic et al [10] present an agent-based virtual classroom. A set of agents is defined for different responsibilities, while collaborated to accomplish a desired task. For instance, one agent is responsible for student classification, and another agent responsible for finding the learning material relevant to students' needs. The concept of a virtual professor is introduced. So the defined classroom represents the interface between the students and a virtual professor and is able to deliver personalized learning materials based on given student profiles.

Krukowski and Kale [7] give a detailed implementation of a virtual classroom using enabling technologies. Different use-case scenarios are discussed, such as a remote lecture, a joint lecture by two or more professors at a distant location, and a remote lab. They present a mechanism to provide a portable hardware and easy to use software toolset as well as how to propel the lectures from the conventional teaching environment to the realm of all interactive multimedia-based virtual classroom.

To improve the real-time performance of an interactive virtual classroom multimedia distance learning system, Deshpande and Hwang [4] describe an extension of well-known bilevel image encoding algorithms to handle the handwritten text video. As a result decoded video frames can be read fast and clearly when encoded at low bit-rate. They design and develop a utility for automatic creation of a synchronized multimedia integration language presentation of the recording of a live class and a test system for handling video, audio, electronic slides, handwritten text materials, and ASCII text to prove the improved effectiveness of the system for students and for the instructors.

Nowadays there are many commercial solutions to e-learning or e-education from different software or service providers although each may have different priorities and features in meeting the requirements of specific customers of an individual software or service provider. These solutions normally combine the necessary web features of administration, teaching, learning, and knowledge sharing with the supports of multipoint videoconferencing, voice over IP, online chats, and whiteboard sharing. Examples can be located in the web sites of PlaceWare [9], 
WebEx [12], Interwise [6], and CentraOne [2], which are well known in providing software or service in the field of e-learning or e-education.

When remote students access the e-learning or e-education servers across continents the fast and reliable delivery of web contents, streaming media, and transaction processing across the Internet could become a problem. Akamai's technologies [1] maintains the largest content delivery networks with web cache servers in 13,000 locations worldwide, resulting the increase of clickthrough by $20 \%$, the reduction of abandonment rates by $10-15 \%$, and transaction completion rate by $15 \%$. WebEx technologies [12] promise the delivery of real-time, interactive, and multimedia communications on the web via worldwide three-tiers WebEx architecture: WebEx Interactive Services, WebEx Interactive Platform, and WebEx Interactive Network.

By addressing the needs of organization training, Docent [3] provides organizations with competency management and performance management modules. Based on personal profiles, job functions, and commercial competency models from "best practices", Docent competency management ensures that individual trainees have the right skill knowledge, and competencies to achieve critical organizational goals. Through tracking individual data associate with knowledge, skills, and competencies, Docent performance management addresses the complete individual performance management life cycle (e.g., alignment of business goals and individual objectives, assessment of knowledge and skill gaps, personalization of "skill gap focused" learning, "On the Job" performance support, and performance evaluation and reward).

\section{3. myCareer - an e-Education System for Professionals}

The myCareer web-based system, developed by GL AgilityTech, Inc., is an e-education system for professionals with the focus on the promise of trainee's satisfaction. It not only combines the general administrative and management features (e.g., school administration, trainee registration, course management, teaching, learning, and knowledge sharing) with the interactive and multimedia supports (i.e., multipoint videoconferencing, voice over IP, online chats, and whiteboard sharing), but also provides individuals with personalized training contents, assignments, and guidelines to meet the needs of individuals. This section discusses how a knowledge-based module is implemented to ensure that the training process can be tailored based on different course expectations, work schedules, work experience, and education backgrounds.

\subsection{Individual Trainee’s Profile}

Each individual has to edit his/her background information before taking any course. Fig. 1 shows the screen for a trainee to update his/her background information. The background information can be updated from time to time and will be shared by all the instructors and the knowledge-based module. It should include all the education data, taken training courses, work experience, and detailed skills related to the courses which will be taken in this training school/center. When he/she completes a course, the course title even its contents will become part of his/her background information. In addition, for each registered course a trainee has to 
edit his/her course expectation. Fig. 2 shows an example given by a trainee who has registered the "Web-based Systems".

\section{Update Background Information Robin Qiu}

Thanks for your up dating your background information.

Background Information:

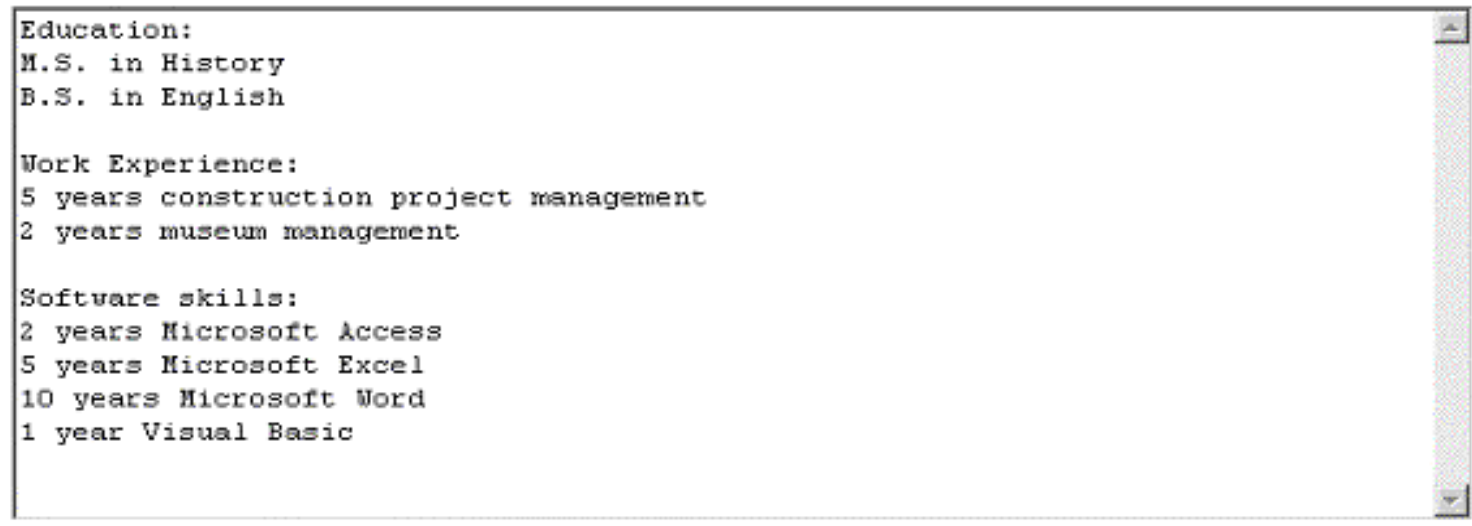

Submit Change | Reset

Figure 1. Individual Background Updating Screen

Web-based Systems is selected.

\section{Update Course Expectation}

Thanks for your updating your course expectation.

Course Expectation Information:

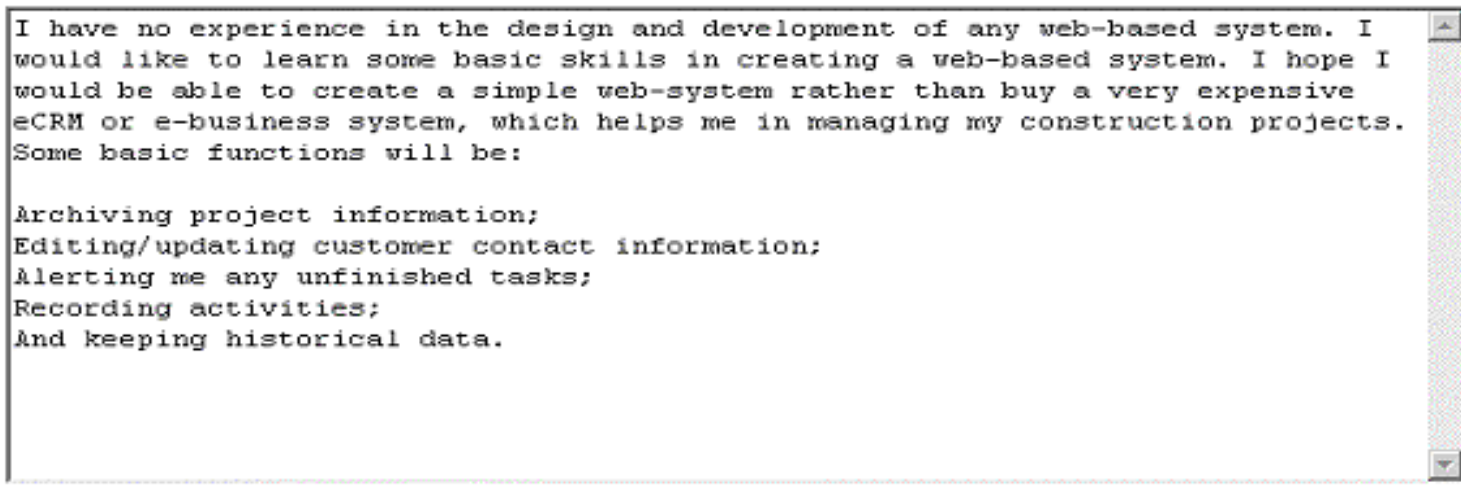

\section{Submit Change Reset}

Figure 2. Course Expectation Updating Screen

Proceedings of the 2002 American Society for Engineering Education Annual Conference \& Exposition 


\subsection{Content Delivery Using the Knowledge-based Module}

A rule-based module is created to deliver the contents to different individuals based on each of their profiles [5, 9]. The contents include course lecture materials, assignments (e.g., homework, projects, reports, etc.), and exams. The general tree structure used to save the contents. Fig. 3 shows an example of a lecture material tree. The structure is constructed based a well-developed course-content XML schema. Part of attributes of each child is production rules, which can be continuously customized through addition, update, or modification by staff or instructors. Furthermore when the feedback from individual is received, the relevant rules for different contents will be modified through a knowledge discovery module.

Through a filter composed of an inference engine and an individual profile retriever, the knowledge base in archived in the XML style is loaded to memory when a trainee logs in the first time. The contents will be different when a different instruction mode is selected (Table 1). The archived individual XML file will be rebuilt whenever there is a change in general contents, production rules, or individual profile. Therefore, the needs of trainees can be optimally satisfied.

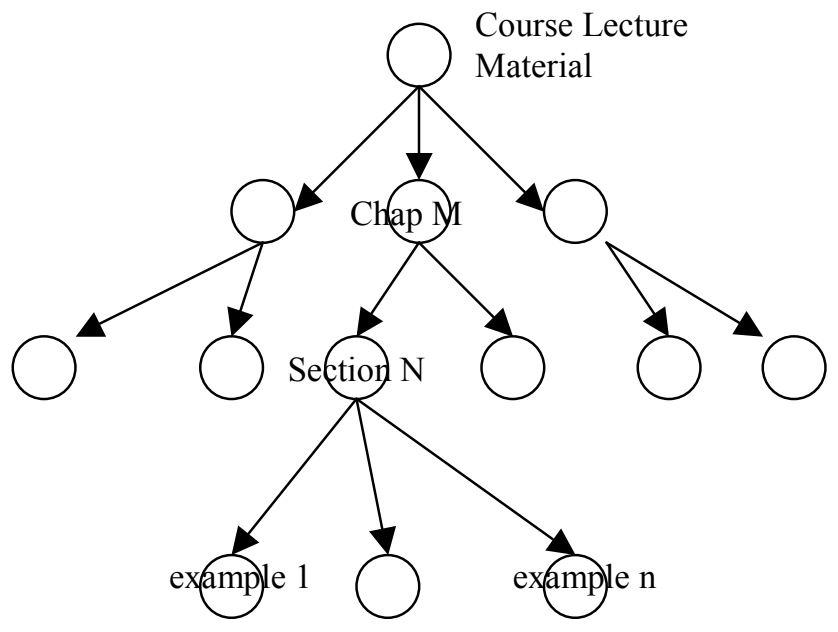

Figure 3. Content, Assignment, and Exam Tree Structure

Table 1. Instructor-led vs. No instructor-led

\begin{tabular}{|l|l|l|}
\hline & \multicolumn{1}{|c|}{ Instructor-led } & \multicolumn{2}{c|}{ No instructor-led } \\
\hline $\begin{array}{l}\text { Lecture } \\
\text { Material }\end{array}$ & $\begin{array}{l}\text { Tailored based group profiles and } \\
\text { met the needs of most attendees }\end{array}$ & $\begin{array}{l}\text { Tailored based on an individual } \\
\text { profile }\end{array}$ \\
\hline Assignment & $\begin{array}{l}\text { Tailored based on an individual } \\
\text { profile }\end{array}$ & $\begin{array}{l}\text { Tailored based on an individual } \\
\text { profile }\end{array}$ \\
\hline Exam & $\begin{array}{l}\text { Tailored based on an individual } \\
\text { profile }\end{array}$ & $\begin{array}{l}\text { Tailored based on an individual } \\
\text { profile }\end{array}$ \\
\hline
\end{tabular}




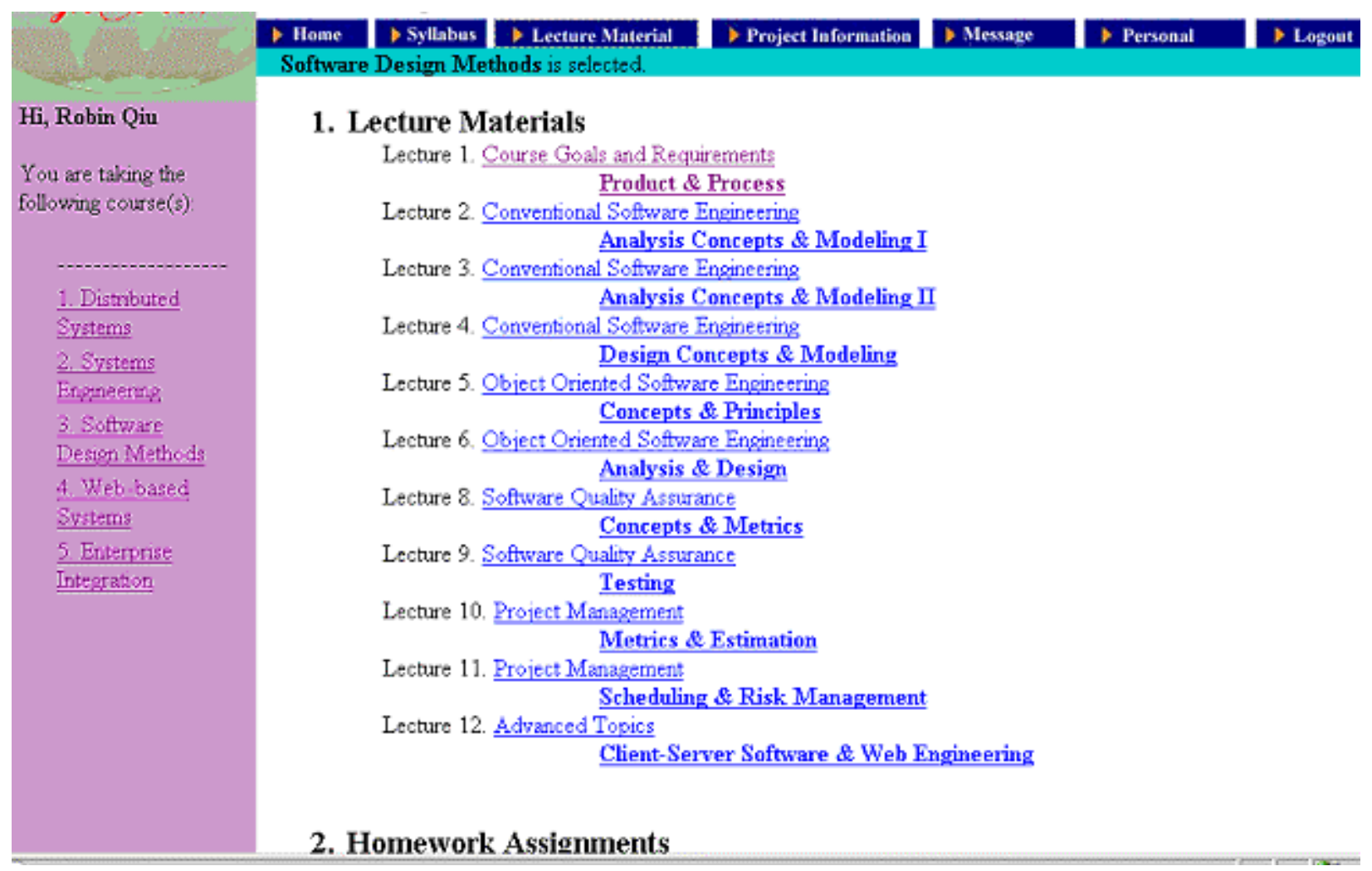

Figure 4. myCareer Main Screen

\subsection{Introduction of Some Main System Features}

The main page of the myCareer system is illustrated in Fig. 4. The left frame lists all the registered courses for the trainee who logs on. The right top lists all the function menus, which get enabled only when a specific course is selected. When only one course is taken, the system defaults the selection of the course automatically. When the "Home" is clicked, the main page shows all the announcements from the instructor of the course, alerts (e.g., assignment, project, or exam due information, teammates messages, etc.), and grading information if it is available. The main page in Fig. 4 shows the retrieved lecture contents when "Lecture Material" is clicked. The material can be delivered in the format of power point with voice, or instructor-led videoconference is it is in session. When the latter is taking place, a whiteboard is available, which is shared by all the attendees on-line.

\section{Conclusions}

When videoconferencing, voice over IP, whiteboard, and on-line chat rooms become off-theshelf technologies, customization and knowledge-based content delivery in e-learning or eeducation become more important features for a professional training school/center in the Internet era, resulting in improving the trainees' satisfaction. This article discussed such an eeducation system taking advantage of the maturity of both XML and intelligence technologies. 
Although the myCareer system was developed for professionals' continue education schools/centers, it can be also effectively used in traditional high institutions.

Bibliographies

1. Akamai, www.akamai.com.

2. Centra, www.centra.com.

3. Docent, www.docent.com.

4. Deshpande, S. and Hwang, J., "A Real-Time Interactive Virtual Classroom Multimedia Distance Learning System," IEEE Transactions on Multimedia, Vol. 3, No. 4, Dec. 2001, pp. 432-444.

5. Hopgood, A., Intelligent System for Engineers and Scientists, $2^{\text {nd }}$ Edition, CRC Press, 2001.

6. Interwise, www.interwise.com.

7. Krukowski, A. and Kale, I., "Virtual Classroom," Proc. of IEEE on Multimedia, 2001, pp. 279-282.

8. PlaceWare, www.placeware.com.

9. Torsun, I., Foundations of Intelligent Knowledge-Based Systems, Academic Press, 1995.

10. Trajkovic, V., Davcev, D., Kimovski, G., and Petanceska, Z., "Web-based Virtual Classroom," Proc. Of IEEE on Multimedia, 2000, pp. 137-146.

11. Tsang, H., Hung, L., and Ng, S., "A Multimedia Distance Learning System on the Internet," Proc. Of IEEE on Multimedia, 1999, pp. 243-246.

12. WebEx, www.WebEx.com.

Robin G. Qiu

Robin Qiu is Assistant Professor of Information Science at Penn State Great Valley. He received his Ph.D. in Computer-Integrated Manufacturing System and Ph.D. Minor in Computer Science from Pennsylvania State University. His disciplines cover Industrial and Manufacturing Engineering, Computer Science, Electrical, and Mechanical Engineering. He has over 10 years of work experience in Computer-Integrated Manufacturing Systems and Enterprise Information Systems and about 40 articles published or presented. 